\title{
The Impact of Hepatitis C Virus Direct-Acting Antivirals on Patient-Reported Outcomes: A Dutch Prospective Cohort Study
}

\author{
Patricia A. M. Kracht - Faydra I. Lieveld - Linde M. Amelung • \\ Carina J. R. Verstraete - Eveline P. Mauser-Bunschoten • \\ Joep de Bruijne - Peter D. Siersema - Andy I. M. Hoepelman • \\ Joop E. Arends · Karel J. van Erpecum
}

Received: June 15, 2018 / Published online: August 3, 2018

(C) The Author(s) 2018

\section{ABSTRACT}

Introduction: Pegylated interferon-based therapy for hepatitis C virus (HCV) negatively impacts nutritional state and patient-reported outcomes (PROs) such as health-related quality of life (HRQL). Clinical trials with direct-acting

Patricia A. M. Kracht and Faydra I. Lieveld contributed equally to this manuscript and are both first author.

Enhanced digital features To view enhanced digital features for this article go to https://doi.org/10.6084/ m9.figshare.6866390.

P. A. M. Kracht · F. I. Lieveld - L. M. Amelung C. J. R. Verstraete · J. de Bruijne - K. J. van Erpecum Department of Gastroenterology and Hepatology, University Medical Center Utrecht Affiliated to Utrecht University, Utrecht, The Netherlands

P. A. M. Kracht · F. I. Lieveld · A. I. M. Hoepelman · J. E. Arends $(\bowtie)$

Department of Internal Medicine and Infectious Diseases, University Medical Center Utrecht Affiliated to Utrecht University, Utrecht, The Netherlands

e-mail: J.E.Arends@umcutrecht.nl

E. P. Mauser-Bunschoten

Department of Benign Haematology, Van Creveldkliniek, University Medical Center Utrecht Affiliated to Utrecht University, Utrecht, The Netherlands

P. D. Siersema

Department of Gastroenterology and Hepatology, Radboud University Medical Center Affiliated to Nijmegen University, Nijmegen, The Netherlands antivirals (DAAs) report significant PRO improvement but real-world data are still scarce. Methods: Prospective cohort study recruiting HCV patients treated with DAAs in 2015-2016. Data at baseline, end of treatment (EOT) and 12 weeks thereafter $\left(\mathrm{FU}_{12}\right)$ included: patient-reported medication adherence; SF-36; Karnofsky Performance Status; paid labour productivity; physical exercise level; nutritional state [by body mass index (BMI) and Jamar hand grip strength (HGS)] and Beliefs about Medicines Questionnaire. Potential factors predicting these PROs were evaluated with multiple regression analysis.

Results: A total of 68 patients were enrolled: $85 \%$ male, median age 57 years, $80 \%$ genotype 1, $40 \%$ cirrhotics, $46 \%$ haemophilia. Both cure rate and patient-reported adherence were $97 \%$. SF-36 Physical Component Summary did not change $\quad(43.2 \pm 11.9, \quad 44.9 \pm 10.3 \quad$ and $44.7 \pm 10.9$ at baseline, EOT and $\mathrm{FU}_{12}$, $p=0.71)$. In contrast, SF-36 mental component summary (MCS) decreased transiently during therapy $\quad(49.2 \pm 11.9, \quad 44.6 \pm 10.3 \quad$ and $49.9 \pm 12.6$ at baseline, EOT and $\mathrm{FU}_{12}$, $p<0.01)$. Concomitant ribavirin-use was the only independent predictor of decreased SF-36 MCS. BMI $(25.7 \pm 4.5$ and $25.6 \pm 4.4$ at baseline and EOT, $p=0.8$ ) and Jamar HGS $(39.7 \pm 13.0,37.4 \pm 11.9$ and $37.9 \pm 13.8$ at baseline, EOT and $\mathrm{FU}_{12}, p=0.56$ ) did not change. 
Conclusion: Our study reveals concomitant ribavirin as the only independent predictor of transient decrease in SF-36 mental HRQL during DAA therapy. In contrast to interferon-based therapy, DAAs do not affect BMI or Jamar HGS.

Keywords: Adherence; Beliefs about Medicines; Direct-acting antivirals; Health-related quality of life; Hepatitis C virus; Karnofsky performance status

\section{INTRODUCTION}

Patient-reported outcomes (PROs) have taken centre stage in the assessment of quality provision in hepatitis C virus (HCV) care [1]. While the main goal of HCV antiviral therapy is to achieve a sustained virological response (SVR), which is considered a surrogate marker for favourable long-term hepatic and extra-hepatic clinical outcomes [2], PROs can demonstrate immediate change in patient's perceived health condition.

A wide variety of PROs such as health-related quality of life (HRQL), labour productivity and physical exercise level are negatively impacted by chronic $\mathrm{HCV}$ infection [3-5]. Even HCV patients with an early fibrosis stage often report impaired HRQL, predominantly attributable to fatigue or depression [4]. Advanced hepatic disease such as cirrhosis is associated with further HRQL impairment [6]. Interferon- and ribavirin-containing regimens also temporarily compromise patient HRQL perception and may lead to a detrimental nutritional state [7], poor therapy adherence and early treatment discontinuation [8]. On the other hand, HCV patients who accomplished successful viral eradication with an interferon-based regimen exhibited improved HRQL following treatment compared to non-responders [9]. The novel direct-acting antivirals (DAAs) significantly reduce patient treatment burden because of shorter therapy courses and a superior side effect profile compared to interferon-containing regimens. The favourable qualities of second-generation DAAs even resulted in PRO improvement as early as 2 weeks after treatment initiation in clinical trials [10]. However, real-world data on PROs in
HCV patients on DAA therapy are still scarce. The current study describes a variety of PROs in a real-world cohort of chronic HCV patients who received DAA treatment.

\section{METHODS}

\section{Patient Selection and Study Design}

All consecutive patients with chronic HCV who received anti-viral treatment with an all-oral DAA regimen at the Department of Gastroenterology of the University Medical Center Utrecht in 2015-2016 were eligible for inclusion in this observational prospective cohort study. Patients with no comprehension of Dutch or English languages and with either HBV or HIV coinfection were excluded.

Patients received DAA therapy in agreement with international guidelines [11, 12]. Medication was dispensed according to usual medical practice and all DAAs were fully reimbursed by the health care insurance (with the exception of the obligatory deductible excess) $[11,12]$. Follow-up visits during therapy with the treating physician were at baseline, after 2 and 4 weeks, and thereafter at 4-week intervals. Both PROs and routine laboratory test results were collected at baseline, end of treatment (EOT) and at 12 weeks after treatment completion $\left(\mathrm{FU}_{12}\right)$. It was aimed to offer support for the patient in cases of any marked decrease in one of the selected PROs (e.g. severe weight loss). The Beliefs About Medicines Questionnaire (BMQ) [13] was collected at baseline and $\mathrm{FU}_{12}$. HCV RNA was assessed using the Cobas Ampliprep and Cobas TaqMan HCV test, Roche (lower limit of detection $15 \mathrm{IU} / \mathrm{mL}$ ). Sustained virological response (SVR) was defined as negative serum HCV RNA 12 weeks post-treatment. Cirrhosis was defined as either Fibroscan $^{\circledR} \geq 12.5 \mathrm{kPa}$ ) [14] or liver histology with METAVIR classification of F4.

All procedures performed in studies involving human participants were in accordance with the ethical standards of the institutional (Medical Ethical Committee of the University Medical Center Utrecht) and/or national research committee and with the 1964 Helsinki 
declaration and its later amendments or comparable ethical standards. Informed consent was obtained from all individual participants included in the study.

\section{Patient-Reported Outcomes}

\section{Health-Related Quality of Life and Performance Status}

The HRQL was assessed using a validated Dutch version of the Short Form-36 (SF-36) [15]. This questionnaire quantifies HRQL with scores ranging from 0 (lowest) to 100 (highest) using eight subscales consisting of: physical functioning (PF), bodily pain (BP), role physical (RP), general health $(\mathrm{GH})$, role emotional (RE), vitality (VT), social functioning (SF) and mental health (MH). The subscales of SF-36 are summarised as physical component summary (PCS) and mental component summary (MCS). Minimal clinically important difference (MCID) for PCS and MCS was defined as a change of $\geq 5 \%$, in accordance with previous literature [16].

The Karnofsky performance status (KPS) scale, which ranges from 0 to 100 , was used to evaluate performance status [17].

\section{Beliefs about Medicines Questionnaire and Treatment Adherence}

Patients' attitude towards medicines was measured at baseline and $\mathrm{FU}_{12}$ using the BMQ [13], which consists of two sections: the BMQ-general and the BMQ-specific which are both scored on a 5-point Likert scale. The BMQ-general assesses beliefs about the harmfulness and overuse of medicine in general. The BMQspecific assesses patients' beliefs about the necessity of the prescribed DAAs for controlling their illness and their concerns about the potential adverse consequences of taking it. Mean scores for each subscale are computed and higher scores indicate stronger agreement. Additionally, the BMQ-specific is categorised into four different groups: "accepting", i.e. necessity score $\geq 2.5$ (high) and concerns score $<2.5$ (low), "ambivalent" i.e. necessity score $\geq 2.5$ (high) and concerns score $\geq 2.5$ (high), "indifferent", i.e. necessity $<2.5$ (low) and concerns $<2.5$ (low), and "skeptical", i.e. necessity score $<2.5$ (low) and concerns score $\geq 2.5$ (high).

Patients' self-reported medication adherence was registered at each visit. Patient-reported treatment adherence was expressed in percentages which were calculated using the following formula: (the number of pills taken during the treatment period divided by the number of pills prescribed by the physician) $\times 100$.

\section{Nutritional State}

Nutritional state was assessed with the voluntary hand grip strength (HGS) according to Jamar. This parameter is a measure of nutritional state [18] and an independent predictor of complications in patients with cirrhosis [19]. The HGS was measured in the dominant hand with a calibrated Jamar dynamometer (Biometrics, Almere, The Netherlands) adjusted for sex, age, and height and compared to a healthy reference population [20-23]. The best of three consecutive measurements was recorded (1 min recovery time between attempts). In addition, data on weight and body mass index (BMI) were collected at baseline and EOT.

\section{Paid Labour Productivity}

For the assessment of paid labour productivity (PLP) patients were asked to provide information on their productivity status. The PLP was defined as full time ( $\geq 36 \mathrm{~h} /$ week), part time $(<36 \mathrm{~h} /$ week) or none, and further categorised as either white collar (physically inactive) or blue collar (physically active) labour. Work impairment was defined as any decrease in working hours during or after DAA therapy.

\section{Physical Exercise}

At each study visit, patients indicated their level of leisure physical exercise (with exclusion of exercise during paid labour working hours). Patients were divided into the following categories according to their physical exercise activity per week: (1) no significant physical exercise ( $<60 \mathrm{~min}$ of exercise); (2) 60-150 min of low-intensity exercise; (3) > $150 \mathrm{~min}$ of lowintensity exercise; (4) 60-150 min of high-intensity exercise; (5) > 150 min of high-intensity exercise. Low-intensity exercise was defined as 
walking and leisure cycling. High-intensity exercise was defined as strength training, running and intense cycling.

\section{Statistical Analysis}

Continuous data are reported as means with standard deviations (SD) or, in cases of a nonGaussian distribution, as medians with interquartile range (IQR). Discrete variables are described as absolute and relative frequencies. Differences between subgroups were tested for statistical significance by independent $t$ test or Mann-Whitney $U$ test, as appropriate.

Paired-samples $t$ test or, in cases of a nonGaussian distribution, the Wilcoxon signed rank test was used to analyse within-group changes between two different time points. In cases of three different time points, a repeated measure ANOVA or a Friedman Test was used in combination with post hoc analysis with Bonferroni correction for multiple testing. Associations between changes from baseline of different continuous outcomes were evaluated with Pearson's correlation coefficient. Univariable and multivariable linear regression analyses were conducted to identify potential factors predicting changes in KPS and SF-36 Summary scores at EOT and $\mathrm{FU}_{12}$ compared to baseline scores. Potential predictors that were analysed, predominantly based on previous literature, included: gender, age, BMI, prior treatment exposure, use of ribavirin, presence of cirrhosis or concomitant haemophilia [10, 24, 25]. Factors with a $p$ value $<0.2$ in univariable analysis were included in subsequent multivariable analysis. Adjusted Beta coefficients with their 95\% confidence intervals (CIs) were calculated. A two-sided $p$ value $<0.05$ was considered statistically significant. SPSS v.4.0 (IBM, Armonk, NY, USA) was used for statistical analyses and GraphPad Prism v.6.0 (GraphPad Software, La Jolla, CA, USA) for creating graphics.

\section{RESULTS}

\section{Patients}

A total of 72 consecutive $\mathrm{HCV}$ patients who received a DAA regimen were considered for inclusion in this study. Four patients were excluded because of language barriers. The remaining 68 participants (Table 1) were predominantly male $(85 \%)$ with a median age of 57 years. Genotypes $1 \mathrm{a}$ and $1 \mathrm{~b}$ were the most prevalent (31\% and 49\%, respectively) and 40\% of patients had compensated cirrhosis. Extrahepatic HCV manifestations such as haematologic, auto-immune or dermatologic conditions were not present in the study population. Concomitant inherited bleeding disorders (haemophilia A or B) were present in $46 \%$. The DAA regimens were sofosbuvir-based in $85 \%$ and ombitasvir/paritaprevir/ritonavir/dasabuvir (3D)-based in $15 \%$. In total, $63 \%$ of all patients received treatment with ribavirin. On average, haemoglobin concentration declined with $1.2 \mathrm{mmol} / \mathrm{L}$ during DAA treatment and haemoglobin concentration had recovered completely to baseline levels at $\mathrm{FU}_{12}$. Seven patients (10\%) had a history of a depressive disorder of which two were on long-term antidepressant treatment. One patient stopped taking the mood stabiliser during DAA therapy due to resolution of symptoms. During the study period, two patients used antidepressants for reasons other than depression such as attention deficit hyperactivity disorder and neuropathic pain. All patients completed the entire treatment period with follow-up 12 weeks posttreatment available. Adherence was 100\% for 66 patients (97\%). The remaining two patients missed one and three doses, respectively, but still achieved a SVR. Total SVR rate was 97\%. Two genotype $1 \mathrm{~b}$ patients with mild fibrosis (FO-F1) exhibited positive HCV RNA within 3-6 months after completion of a 3D-based regimen. One case was classified as a relapse and the other as a re-infection with a genotype switch to $1 \mathrm{a}$. 
Table 1 Characteristics of chronic hepatitis C patients and direct-acting antiviral treatments

\begin{tabular}{|c|c|}
\hline & $n=68$ \\
\hline Age (years), median (IQR) & $57(49-64)$ \\
\hline Male gender, $n(\%)$ & $58(85)$ \\
\hline \multicolumn{2}{|l|}{ Ethnic descent, $n(\%)$} \\
\hline Caucasian & $63(93)$ \\
\hline North African/Middle East & $4(6)$ \\
\hline Other & $1(1)$ \\
\hline \multicolumn{2}{|l|}{ Baseline blood tests, median (IQR) } \\
\hline $\operatorname{ALT}(\mathrm{U} / \mathrm{L})$ & $74(41-124)$ \\
\hline Albumin $(\mathrm{g} / \mathrm{L})$ & $42.2(40.2-44.3)$ \\
\hline Bilirubin $(\mu \mathrm{mol} / \mathrm{L})$ & $11(8-14)$ \\
\hline Prothrombin time $(s)$ & $13.7(13.2-14.4)$ \\
\hline Thrombocytes $\left(10^{9} / \mathrm{L}\right)$ & $182(135-239)$ \\
\hline Cirrhosis, $n(\%)$ & $27(40)$ \\
\hline Child-Pugh A, $n(\%)$ & $27(100)$ \\
\hline MELD-score, median (IQR) & $7(6-9)$ \\
\hline Haemophilia, $n(\%)$ & $31(46)$ \\
\hline \multicolumn{2}{|l|}{ HCV genotype, $n(\%)$} \\
\hline $1 \mathrm{a}$ & $21(31)$ \\
\hline $1 b$ & $33(49)$ \\
\hline 2 & $2(3)$ \\
\hline 3 & $7(10)$ \\
\hline 4 & $5(7)$ \\
\hline $\begin{array}{l}\text { Baseline HCV RNA }(\log 10 \mathrm{IU} / \mathrm{mL}) \\
\text { median (IQR) }\end{array}$ & $6.3(6.0-6.5)$ \\
\hline Peg-IFN/RBV experienced, $n(\%)$ & $34(50)$ \\
\hline \multicolumn{2}{|l|}{ DAA treatment, $n(\%)$} \\
\hline Sof/RBV & $3(4)$ \\
\hline Sof/Sim \pm RBV & $12(18)$ \\
\hline Sof/Ldv $\pm \mathrm{RBV}$ & $17(25)$ \\
\hline Sof/Dac/RBV & $26(38)$ \\
\hline $3 \mathrm{D} \pm \mathrm{RBV}$ & $10(15)$ \\
\hline Ribavirin, $n(\%)$ & $43(63)$ \\
\hline
\end{tabular}

Table 1 continued

\begin{tabular}{lc}
\hline & $\boldsymbol{n}=\mathbf{6 8}$ \\
\hline Treatment duration, $n(\%)$ & $60(88)$ \\
12 weeks & $8(12)$ \\
24 weeks & $2.4(1.7-3.4)$ \\
Ribavirin concentration at week $8(\mathrm{mg} /$ & \\
L), median (IQR) & \\
\hline
\end{tabular}

$A L T$ alanine aminotransferase; $B M I$ body mass index; $D A A$ direct-acting antiviral; $D a c$ daclatasvir; $H B V$ hepatitis $\mathrm{B}$ virus; $H I V$ human immunodeficiency virus; $I Q R$ interquartile range; $L d v$ ledipasvir; $M E L D$ Model for EndStage Liver Disease; Peg-IFB pegylated-interferon; RBV ribavirin; Sim simeprevir; Sof sofosbuvir; $3 D$ ombitasvir, paritaprevir, ritonavir and dasabuvir

\section{Health-Related Quality of Life and Performance Status}

At baseline, the physical component summary (PCS) was impaired in comparison with the general Dutch population [15]; however, there was no subsequent change in PCS during or after DAA therapy $(43.2 \pm 11.9,44.9 \pm 10.3$, and $44.7 \pm 10.9$ at baseline, EOT and $\mathrm{FU}_{12}$, respectively, $p=0.71$ ) (Table 2 ). Patients with an inherited bleeding disorder tended to have lower PCS at baseline than those without an inherited bleeding disorder $(40.7 \pm 10.5$ vs. $45.5 \pm 9.6, p=0.06$ ), and this discrepancy was also observed during and after DAA treatment. In multivariable analysis, higher BMI was found predictive for increase of PCS score at EOT compared to baseline $(p<0.05)$.

The mental component summary (MCS) was similar to the general population at baseline but decreased transiently during therapy $(49.2 \pm 11.9,44.6 \pm 10.3$ and $49.9 \pm 12.6$ at baseline, EOT and $\mathrm{FU}_{12}$ respectively, $p<0.05$ ) (Table 2). At baseline, patients with an inherited bleeding disorder had substantially higher MCS score in comparison with the non-haemophilic patients $(54.7 \pm 10.1$ vs. $44.1 \pm 11.1, p<0.05)$. In contrast, cirrhotic patients had significantly 
Table 2 SF36-components during DAA treatment

\begin{tabular}{llllr}
\hline SF-36-components & Baseline & EOT & FU $_{\mathbf{1 2}}$ & \multicolumn{1}{c}{$\boldsymbol{p}^{\mathbf{a}}$} \\
\hline Physical functioning & $70.3 \pm 25.0$ & $70.7 \pm 21.1$ & $71.5 \pm 26.9$ & 0.42 \\
Role physical & $63.2 \pm 37.5$ & $49.1 \pm 43.2^{\mathrm{b}}$ & $69.0 \pm 40.6$ & $<0.05$ \\
Bodily pain & $68.7 \pm 23.3$ & $70.9 \pm 26.6$ & $69.7 \pm 24.4$ & 0.73 \\
General health & $54.6 \pm 21.4$ & $58.5 \pm 22.0$ & $58.8 \pm 21.8$ & 0.51 \\
Social functioning & $75.7 \pm 24.6$ & $72.8 \pm 24.1$ & $79.0 \pm 23.6^{\mathrm{c}}$ & $<0.05$ \\
Role emotional & $75.6 \pm 35.6$ & $66.1 \pm 42.1$ & $75.7 \pm 39.8^{\mathrm{c}}$ & $<0.05$ \\
Mental health & $75.4 \pm 17.7$ & $68.7 \pm 21.8^{\mathrm{b}}$ & $76.6 \pm 18.0$ & $<0.05$ \\
Vitality & $59.8 \pm 21.3$ & $54.3 \pm 24.1^{\mathrm{b}}$ & $65.7 \pm 22.1^{\mathrm{d}}$ & $<0.05$ \\
Physical component summary & $43.2 \pm 11.9$ & $44.9 \pm 10.3$ & $44.7 \pm 10.9$ & 0.71 \\
Mental component summary & $49.2 \pm 11.9$ & $44.6 \pm 10.3^{\mathrm{b}}$ & $49.9 \pm 12.6$ & $<0.05$ \\
\hline
\end{tabular}

Data presented as mean \pm SD. Significant differences in post hoc analysis $(p<0.05)$ are reported

a The $p$ value is reported for the repeated measures analysis (ANOVA or Friedman)

b From baseline and $\mathrm{FU}_{12}$ values

c From EOT values

d From baseline and EOT values

Table 3 Factors predicting decrease in SF-36 Mental Component Summary at end of DAA treatment compared to baseline

\begin{tabular}{|c|c|c|c|c|c|c|}
\hline & \multicolumn{3}{|c|}{ Univariable analysis } & \multicolumn{3}{|c|}{ Multivariable analysis } \\
\hline & Beta-coefficient & CI & $p$ & Beta-coefficient & CI & $p$ \\
\hline Age & -0.07 & -0.37 to +0.23 & 0.64 & & & \\
\hline Female gender & 8.99 & +1.09 to +16.89 & 0.03 & 7.17 & -0.46 to +14.80 & 0.07 \\
\hline BMI & -0.50 & -1.16 to +0.17 & 0.14 & 0.00 & -0.64 to +0.64 & 1.0 \\
\hline Treatment experienced & -4.53 & -10.48 to +1.42 & 0.13 & -2.65 & -8.42 to +3.12 & 0.36 \\
\hline Cirrhosis & -1.65 & -7.91 to +4.61 & 0.60 & & & \\
\hline Hemophilia & -1.98 & -8.05 to +4.09 & 0.52 & & & \\
\hline Ribavirin therapy & -6.03 & -12.03 to -0.04 & 0.05 & -7.74 & -13.73 to -1.75 & 0.01 \\
\hline
\end{tabular}

Uni- and multivariable analysis of predicting factors and SF-36 Mental Component Summary scores at end of treatment with reference to baseline values. Significant values $(p<0.05)$ in bold

CI confidence interval

lower MCS scores at baseline $(45.3 \pm 12.8$ vs. $51.9 \pm 10.6, p<0.05)$ than those without cirrhosis. In the multivariable analysis, concomitant ribavirin use was the only independent predictor of decreased MCS during therapy $(p<0.05) \quad$ (Table 3$)$ Although ribavirin recipients experienced a greater decline in haemoglobin concentration than those treated with ribavirin-free regimens $(-1.7$ vs. $-0.4 \mathrm{mmol} / \mathrm{L}, \quad p<0.05)$, the haemoglobin decline was not correlated with the decrease in MSC during DAA treatment $(r=0.14, p=0.31)$. 


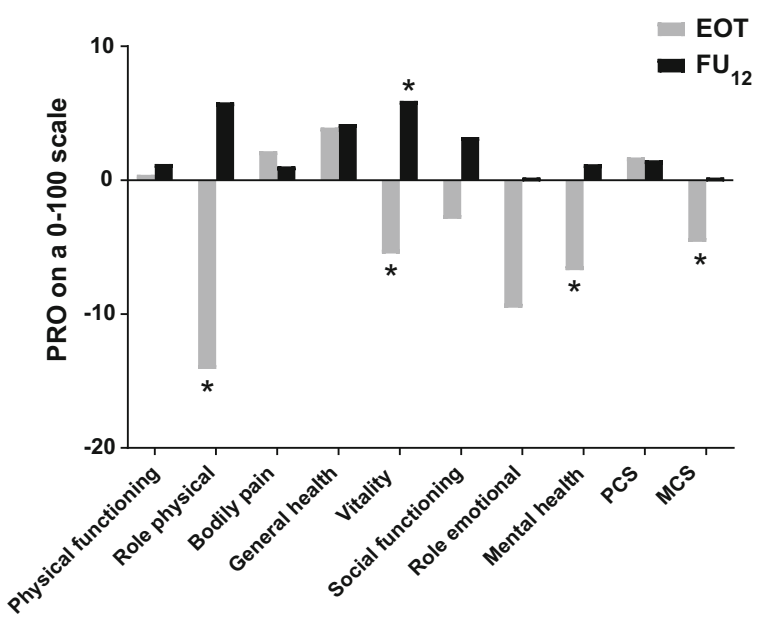

Fig. 1 Changes of SF-36 components during and 12 weeks after direct-acting antiviral therapy compared to baseline. Mean change in SF-36 component scores during and after treatment compared to baseline values. $E O T$ end of treatment, $F U_{12} 12$ weeks after end of treatment. ${ }^{*} p<0.05$ in the repeated measures analysis (ANOVA or Friedman) with post hoc analyses

Patients not receiving ribavirin had stable MCS levels during treatment $(53.2 \pm 10.8$, $50.3 \pm 11.0$ and $52.9 \pm 11.2$ at baseline, EOT and $\mathrm{FU}_{12}$ respectively, $p=0.28$ ).

The eight SF-36 subscales generally decreased during treatment with improvement 12 weeks after end of therapy (Fig. 1). The SF-36 vitality scale, (considered the most affected component of SF-36 in HCV patients[16]), was the only subscale that demonstrated significant improvement at $\mathrm{FU}_{12}$ compared to baseline $(+5.9$, CI 1.2-10.0, $p<0.05)$.

The overall Karnofsky performance status (KPS) score at baseline was high $(92.3 \pm 11.7)$ although patients with cirrhosis had a considerable lower KPS level than non-cirrhotics $(87.0 \pm 13.8$ vs. $96.1 \pm 7.7, p<0.05)$. Similar to the SF-36 MCS score, KPS showed a significant transient decrease during treatment with subsequent recovery $(92.3 \pm 11.7,84.2 \pm 13.7$ and $90.3 \pm 11.8$ at baseline, EOT and $\mathrm{FU}_{12}$ respectively, $p<0.05)$. No predictive factors were identified for decline in KPS during treatment in multiple regression analysis.
Table 4 Attitude of patients with chronic hepatitis C infection towards direct-acting antiviral therapy

\begin{tabular}{lcc}
\hline & Baseline & $\mathbf{F U}_{\mathbf{1 2}}{ }^{\mathbf{a}}$ \\
\hline Accepting & $18(37)$ & $27(56)$ \\
Ambivalent & $19(39)$ & $10(20)$ \\
Indifferent & $3(6)$ & $10(20)$ \\
Skeptical & $9(18)$ & $2(4)$ \\
\hline
\end{tabular}

Attitude towards DAA therapy assessed with the BMQspecific. Results are given for patients with complete evaluation at two time-points $(n=49) . \mathrm{FU}_{12}, 12$ weeks after follow-up. Data presented as counts with relative frequencies

a Overall difference at $\mathrm{FU}_{12}$ compared to baseline was non-significant $(p=0.1)$ (Wilcoxon signed rank test)

\section{Beliefs About Medicines}

Paired BMQ results at baseline and 3 months after end of therapy were available for 49 patients (72\%). According to the BMQ-specific questionnaire, $37 \%$ of all patients had an 'accepting' attitude towards DAA therapy which increased to $55 \%$ at $\mathrm{FU}_{12}$ (Table 4). This can be explained by a decrease in the proportion of patients with 'high concerns' about the potential adverse consequences of taking DAAs from $56 \%$ at baseline to $25 \%$ at EOT. Overall, changes in attitude towards DAA at $\mathrm{FU}_{12}$ compared to baseline did not reach significance $(p=0.10)$. When considering beliefs about medication in general, treatment with DAAs had no significant impact on the beliefs about harmfulness $\left(2.3 \pm 0.7\right.$ and $2.3 \pm 0.6$ at baseline and $\mathrm{FU}_{12}$, $p=0.65)$ and overuse $(2.5 \pm 0.6$ and $2.6 \pm 0.8$ at baseline and $\mathrm{FU}_{12}, p=0.51$ ).

\section{Nutritional State}

Baseline BMI indicated normal weight (BMI $\left.18.5-25 \mathrm{~kg} / \mathrm{m}^{2}\right)$, overweight (BMI $>25-30 \mathrm{~kg} /$ $\mathrm{m}^{2}$ ) and obesity (BMI $\left.>30 \mathrm{~kg} / \mathrm{m}^{2}\right)$ in $44 \%, 40 \%$ and $16 \%$ of patients, respectively. Overall, no substantial BMI change was observed during therapy $(25.7 \pm 4.5$ and $25.6 \pm 4.4$ at baseline and EOT, respectively, $p=0.78$ ) and severe 


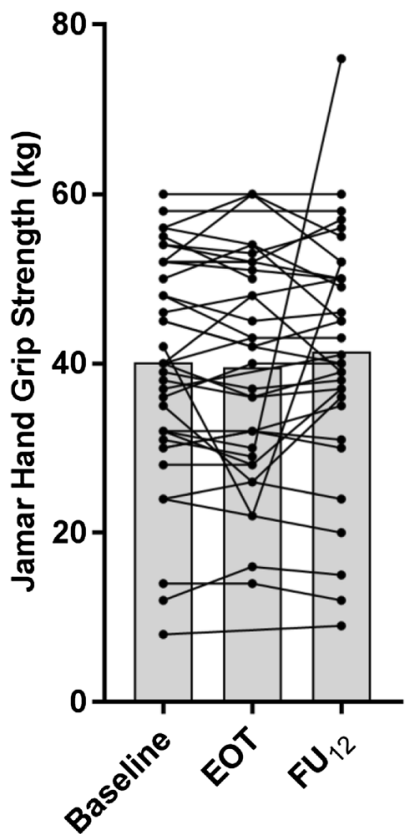

Fig. 2 Hand grip strength according to Jamar before direct-acting antiviral therapy, at end of treatment and at 12 weeks follow-up. Bars indicate means. Black circles with connecting lines indicate individual patients. EOT end of treatment, $F U_{12} 12$ weeks after end of treatment

weight loss (i.e. $\geq 10 \%$ of basal values) did not occur.

In 36 patients, hand grip strength (HGS) measurements according to Jamar were available at baseline, EOT and/or $\mathrm{FU}_{12}$. At baseline, HGS was sufficient in $52-88 \%$ of the group, depending on reference values that were used, and this ranged between $40 \%$ and $78 \%$ at both EOT and at $\mathrm{FU}_{12}[21,23]$. Mean HGS during antiviral therapy did not change $(39.7 \pm 13.0$, $37.4 \pm 11.9$ and $37.9 \pm 13.8$ at baseline, EOT and $\mathrm{FU}_{12}$ respectively, $p=0.56$ ). A total of 5 patients experienced a reduction of greater than $10 \%$ in HGS at EOT; however, this returned to baseline levels for all but one patient at $\mathrm{FU}_{12}$ (Fig. 2).

\section{Paid Labour Productivity and Physical Exercise}

Data on paid labour productivity, physical exercise and performance status are given in Table 5. At baseline, paid labour was performed by $50 \%$ ( $54 \%$ full time white collar, $6 \%$ full time blue collar, $32 \%$ part-time white collar and $8 \%$ part-time blue collar).

After therapy completion, complete loss of labour and work impairment were reported by $8 \%$ and $19 \%$ of all patients with paid labour at baseline, respectively. All three patients with complete loss of labour had an inherited bleeding disorder. At $\mathrm{FU}_{12}$, two of these three had returned to working the same hours as before treatment initiation.

Prior to antiviral therapy, $32 \%$ of all patients performed no significant leisure physical exercise at all, and this proportion increased thereafter $\left(52 \%\right.$ and $59 \%$ at EOT and $\mathrm{FU}_{12}$, respectively). Before initiation of therapy, those $\mathrm{HCV}$ patients who performed exercise mostly trained at low intensity (76\%) and a smaller proportion performed high-intensity exercise (24\%). Abandonment of all significant physical exercise during DAA treatment occurred in $48 \%$ of those patients who exercised before DAA therapy. At $\mathrm{FU}_{12}$, exercise was reinitiated by $22 \%$ of these patients. There was no difference in haemoglobin concentration decline during treatment in patients who had stopped exercising compared to those who continued $(-1.3$ vs. $-1.0 \mathrm{mmol} / \mathrm{L}, p=0.40)$. Overall, the level of physical exercise during DAA treatment changed significantly $(p<0.05)$.

\section{DISCUSSION}

In addition to efficacy and safety data, PROs are important in quantifying the impact and value of DAA therapy $[26,27]$. Although clinical trial data suggest that PRO improvement in $\mathrm{HCV}$ patients can be accomplished even shortly after DAA treatment initiation [10], this has yet to be confirmed by real-world evidence.

The main finding of our study was that HRQL remained stable during and after DAA treatment when considering the PCS. Several previous clinical DAA trials demonstrate significant improvement of PCS at EOT and/or $\mathrm{FU}_{12}$ [28-30]. However, a temporary on-treatment decline in PCS during sofosbuvir/ribavirin treatment has also been reported [24]. Differences between our current study and previous 
Table 5 Paid labour productivity and physical exercise during and after direct-acting antiviral therapy

\begin{tabular}{|c|c|c|c|c|}
\hline & Baseline & EOT & $\mathbf{F U}_{12}$ & $p^{\mathbf{a}}$ \\
\hline Paid labour productivity, $n(\%)$ & & & $\mathrm{b}$ & 0.12 \\
\hline None & $34(50)$ & $35(51)$ & $28(48)$ & \\
\hline White collar & $29(43)$ & $26(38)$ & $23(39)$ & \\
\hline Blue collar & $5(7)$ & $7(9)$ & $8(14)$ & \\
\hline Paid labour productivity h/week, median $(\mathrm{IQR})^{\mathrm{c}}$ & $36(26-40)$ & $36(19-40)$ & $40(24-40)$ & 0.63 \\
\hline Physical exercise, $n$ (\%) & & & $\mathrm{d}$ & 0.01 \\
\hline None & $22(32)$ & $35(52)$ & $36(59)$ & \\
\hline Low intensity, $60-150 \mathrm{~min}$ & $17(25)$ & $10(15)$ & $11(18)$ & \\
\hline Low intensity, $150-240 \mathrm{~min}$ & $18(27)$ & $11(16)$ & $7(11)$ & \\
\hline High intensity, 60-150 min & $2(3)$ & $7(10)$ & $4(7)$ & \\
\hline High intensity, 150-240 & $9(13)$ & $5(7)$ & $3(5)$ & \\
\hline
\end{tabular}

$E O T$ end of treatment, $F U_{12} 12$ weeks after follow-up, $I Q R$ interquartile range

${ }^{a} p$ value for overall changes during treatment (Friedman test)

b Data on paid labour productivity at $\mathrm{FU}_{12}$ was available for 59 patients

c Data depicted for those with paid labour at baseline, EOT or FU 12

d Data on physical exercise at $\mathrm{FU}_{12}$ was available for 61 patients

trials could be related to a different patient selection. For instance, a large proportion of our patients had an inherited bleeding disorder and this subgroup exhibited lower PCS scores throughout the treatment and follow-up period compared to those without an inherited bleeding disorder. The mental component summary (MCS) revealed an important on-treatment decline in our patients with complete recovery at follow-up. Concomitant ribavirin was the only independent predictor of the temporary decline in MCS. Previous literature reports similar and reversible on-treatment declines in the MCS in HCV patients treated with a ribavirincontaining regimen. Of note, those patients who did not receive ribavirin in these clinical trials showed an early increase in the MCS after the start of DAA treatment $[28,31]$. Patients in our study with a ribavirin-free regimen had no significant change in MCS level during therapy compared to baseline. With respect to the individual SF-36 domains, vitality demonstrated the most pronounced and clinically important improvement at $\mathrm{FU}_{12}$ compared to baseline $(+5.9)$, which is in accordance with previous literature that describes vitality as one of the key SF-36 domains affected by HCV [16].

Patients with an inherited bleeding disorder comprise a large proportion of our cohort with excellent SVR-rates of 97\%, which is in agreement with other studies in this patient category $[32,33]$. To our knowledge, this is the first realworld report on PROs of HCV patients with an inherited bleeding disorder during DAA treatment. Patients with an inherited bleeding disorder had substantially lower PCS scores in comparison with the other patients. This could relate to the consequences of haemophilia (e.g. disabling arthropathy). In contrast, their MCS scores at each time-point during the study period were significantly higher than in the other patients. MCS scores in patients with haemophilia have previously been described to be relatively high in comparison with the countryspecific normative scores [34, 35]. Since quality of life measurement expresses the patient's subjective perception of their level of functioning compared to what they believe to be optimal, we hypothesise that the relatively high MSC scores in haemophiliacs in our study 
reflect a high degree of chronic disease acceptance in this well-adapted patient group.

It has been reported that patients' beliefs about medicines as assessed with the BMQ is related to medication adherence in inflammatory bowel disease and depressive disorders $[36,37]$. In this cohort, the selection of patients with an 'accepting' attitude towards DAAs improved from $37 \%$ at baseline to $55 \%$ at $\mathrm{FU}_{12}$. This was mainly due to a decrease in 'high concerns' about the potential adverse consequences of taking DAAs from $56 \%$ at baseline to $25 \%$. At $\mathrm{FU}_{12}, 76 \%$ of patients scored 'high' on beliefs about DAA necessity and $75 \%$ scored 'low' on concerns about DAAs, so both domains would have to be addressed equally to improve the overall patient acceptance of DAAs in the future. The relationship between patients' attitude and adherence could not be investigated since 97\% of this cohort reported perfect adherence $(=100 \%)$. This may be an overestimation of true adherence since adherence in this study was patient-reported and therefore subject to recall bias. Nevertheless, non-adherence does not appear a major problem in DAA therapy [38, 39].

Malnutrition can predict complications in patients with cirrhosis [19, 22] and severe weight loss $(>10 \%)$ during treatment often occurred in the interferon era [7]. To our knowledge, our study is the first report on nutritional state of HCV patients during allDAA treatment. In our cohort, no significant changes in mean BMI and hand grip strength according to Jamar were found.

Infection with $\mathrm{HCV}$ imposes an economic burden with impaired work productivity $[3,40,41]$. Our study shows a high unemployment rate of $50 \%$ in patients with chronic HCV at baseline, which is in line with large international health surveys $(7-74 \%)[3,42,43]$ and a previous study in the Netherlands (54\%) [44]. Work impairment (i.e. decrease in working hours) in our cohort occurred in 15\% during treatment which is lower than previously described (26-30\%) [5, 42, 43]. However, actual work impairment may be higher as patients only reported on absenteeism and not presenteeism (i.e. being on the job but with diminished work productivity because of illness) which has been documented to be the predominant factor in work impairment in HCV patients receiving interferon-based therapy $[5,42,43]$. About one-third (32\%) of all HCV patients performed no leisure physical exercise at baseline, comparable with previous literature $(32-52 \%)$ [3, 43].

Our study has several strengths and limitations. First of all, it provides results on a wide range of validated PRO measures that were collected prospectively. Secondly, it contributes to the scarce knowledge on PROs in HCV patients with an inherited bleeding disorder. On the other hand, the inclusion of patients with an inherited bleeding disorder might cause somewhat diminished generalisability of the results. Of further note, patients with decompensated cirrhosis were not included in this study. Although we made efforts to minimise the amount of loss to follow-up, there are still some missing values in a number of outcomes variables which may have influenced our results. Finally, the relatively small number of patients may have prohibited us from demonstrating overall improvement in PROs and also precluded analysis of the potential effects of different DAA regimens on PRO values.

\section{CONCLUSION}

In conclusion, our real-world experience with DAAs reveals reversible decline of the SF-36 Mental Component Summary without change in the Physical Component Summary or the nutritional state. Concomitant ribavirin therapy was the only predictive factor for decreased Mental Component Summary.

\section{ACKNOWLEDGEMENTS}

We thank all the participants of our study for their contribution and cooperation.

Funding. This research received no specific grant from any funding agency in the public, commercial or not-for-profit sectors. No funding or sponsorship was received for the publication of this article. 
Authorship. All named authors meet the International Committee of Medical Journal Editors (ICMJE) criteria for authorship for this article, take responsibility for the integrity of the work as a whole, and have given their approval for this version to be published.

Authors' Contributions. Andy I.M. Hoepelman: critical revision of the manuscript; Carina J.R. Verstraete: acquisition of data, critical revision of the manuscript; Eveline P. Mauser-Bunschoten: critical revision of the manuscript; Faydra I. Lieveld: acquisition of data, analysis and interpretation of data, drafting of the manuscript, critical revision of the manuscript; Joop E. Arends: critical revision of the manuscript; Joep de Bruijne: critical revision of the manuscript; Karel J. van Erpecum: analysis and interpretation of data, drafting of the manuscript, critical revision of the manuscript; Linde M. Amelung: acquisition of data, analysis and interpretation of data, critical revision of the manuscript; Patricia A.M. Kracht: acquisition of data, analysis and interpretation of data, drafting of the manuscript, critical revision of the manuscript; Peter D. Siersema: critical revision of the manuscript. All authors have read and approved the final article.

Disclosures. Andy I.M. Hoepelman: advisory boards: Abbvie, BMS, Gilead, Janssen, MSD; consultancy: AbbVie; financial support for HCV retrieval project from Abbvie, BMS, Gilead and MSD; Eveline P. Mauser-Bunschoten: has received unrestricted research/educational support from CSL Behring, Bayer, Baxter, Griffols, Novo Nordisk, Pfizer, Biotest, Roche and Sanquin; Joop E. Arends: advisory boards: Abbvie, BMS, Gilead, Janssen, MSD and ViiV; research grants: AbbVie, BMS; Karel J. van Erpecum: advisory boards: Abbvie, BMS, Gilead, JanssenCilag. Patricia A.M. Kracht, Faydra I. Lieveld, Linde Amelung, Carina J.R. Verstraete, Joep de Bruijne, and Peter D. Siersema have nothing to disclose.

Compliance with Ethics Guidelines. All procedures performed in studies involving human participants were in accordance with the ethical standards of the institutional
(Medical Ethical Committee of the University Medical Center Utrecht) and/or national research committee and with the 1964 Helsinki declaration and its later amendments or comparable ethical standards. Informed consent was obtained from all individual participants included in the study.

Data Availability. The dataset analysed during the current study is available from the corresponding author on reasonable request.

Open Access. This article is distributed under the terms of the Creative Commons Attribution-NonCommercial 4.0 International License (http://creativecommons.org/licenses/ by-nc/4.0/), which permits any noncommercial use, distribution, and reproduction in any medium, provided you give appropriate credit to the original author(s) and the source, provide a link to the Creative Commons license, and indicate if changes were made.

\section{REFERENCES}

1. Marcellin F, Roux P, Protopopescu C, Duracinsky M, Spire B, Carrieri MP. Patient-reported outcomes with direct-acting antivirals for the treatment of chronic hepatitis C: current knowledge and outstanding issues. Expert Rev Gastroenterol Hepatol. 2017;11:259-68.

2. van der Meer AJ, Veldt BJ, Feld JJ, Wedemeyer H, Dufour JF, Lammert F, Duarte-Rojo A, et al. Association between sustained virological response and all-cause mortality among patients with chronic hepatitis $\mathrm{C}$ and advanced hepatic fibrosis. JAMA. 2012;308:2584-93.

3. daCosta DiBonaventura $\mathrm{M}$, Wagner J-S, Yuan $\mathrm{Y}$, L'Italien G, Langley P, Ray Kim W. The impact of hepatitis $\mathrm{C}$ on labor force participation, absenteeism, presenteeism and non-work activities. J Med Econ. 2011;14:253-61.

4. Gutteling JJ, De Man RA, Van der Plas SM, Schalm SW, Busschbach JJ, Darlington A-SE. Determinants of quality of life in chronic liver patients. Aliment Pharmacol Ther. 2006;23:1629-35.

5. Vietri J, Prajapati G, El Khoury AC. The burden of hepatitis $\mathrm{C}$ in Europe from the patients' perspective: a survey in 5 countries. BMC Gastroenterol. 2013;13:16. 
6. Younossi ZM, Boparai N, Price LL, Kiwi ML, McCormick M, Guyatt G. Health-related quality of life in chronic liver disease: the impact of type and severity of disease. Am J Gastroenterol. 2001;96:2199-205.

7. Huisman EJ, van Hoek $B$, van Soest $H$, van Nieuwkerk KM, Arends JE, Siersema PD, van Erpecum KJ. Preventive versus 'on-demand' nutritional support during antiviral treatment for hepatitis C: a randomized controlled trial. J Hepatol. 2012;57:1069-75.

8. Bernstein D, Kleinman L, Barker CM, Revicki DA, Green J. Relationship of health-related quality of life to treatment adherence and sustained response in chronic hepatitis $\mathrm{C}$ patients. Hepatology. 2002;35:704-8.

9. Bezemer G, Van Gool AR, Verheij-Hart E, Hansen BE, Lurie Y, Esteban JI, Lagging M, et al. Long-term effects of treatment and response in patients with chronic hepatitis $\mathrm{C}$ on quality of life. An international, multicenter, randomized, controlled study. BMC Gastroenterol. 2012;12:11.

10. Younossi ZM, Stepanova M, Marcellin P, Afdhal N, Kowdley KV, Zeuzem S, Hunt SL. Treatment with ledipasvir and sofosbuvir improves patient-reported outcomes: results from the ION-1, -2 , and -3 clinical trials. Hepatology. 2015;61:1798-808.

11. European Association For The Study Of The Liver. EASL recommendations on treatment of hepatitis C 2015. J Hepatol. 2015;63:199-236.

12. AASLD/IDSA HCV Guidance Panel. Hepatitis C guidance: AASLD-IDSA recommendations for testing, managing, and treating adults infected with hepatitis C virus. Hepatology. 2015;62:932-54.

13. Horne R, Weinman J, Hankins M. The beliefs about medicines questionnaire: the development and evaluation of a new method for assessing the cognitive representation of medication. Psychol Health. 1999;14:1-24.

14. Castera L, Forns X, Alberti A. Non-invasive evaluation of liver fibrosis using transient elastography. J Hepatol. 2008;48:835-47.

15. Aaronson NK, Muller M, Cohen PD, Essink-Bot ML, Fekkes M, Sanderman R, Sprangers MA, et al. Translation, validation, and norming of the Dutch language version of the SF-36 Health Survey in community and chronic disease populations. J Clin Epidemiol. 1998;51:1055-68.

16. Spiegel BMR, Younossi ZM, Hays RD, Revicki D, Robbins S, Kanwal F. Impact of hepatitis C on health related quality of life: a systematic review and quantitative assessment. Hepatology. 2005;41:790-800.

17. Karnofsky DA, Burchenal JH. Evaluation of chemotherapeutic agents. In: Macleod CM (Ed). Columbia University Press: New York, 1949.

18. Norman K, Stobäus N, Gonzalez MC, Schulzke J-D, Pirlich M. Hand grip strength: outcome predictor and marker of nutritional status. Clin Nutr. 2011;30:135-42.

19. Huisman EJ, Trip EJ, Siersema PD, van Hoek B, van Erpecum KJ. Protein energy malnutrition predicts complications in liver cirrhosis. Eur J Gastroenterol Hepatol. 2011;23:982-9.

20. Mathiowetz V, Weber K, Volland G, Kashman N. Reliability and validity of grip and pinch strength evaluations. J Hand Surg Am. 1984;9:222-6.

21. Peters MJH, van Nes SI, Vanhoutte EK, Bakkers $M$, van Doorn PA, Merkies ISJ, Faber CG, et al. Revised normative values for grip strength with the Jamar dynamometer. J Peripher Nerv Syst. 2011;16:47-50.

22. Álvares-da-Silva $M$ ári. R, Reverbel da Silveira $T$. Comparison between handgrip strength, subjective global assessment, and prognostic nutritional index in assessing malnutrition and predicting clinical outcome in cirrhotic outpatients. Nutrition 2005; $21: 113-7$.

23. Webb AR, Newman LA, Taylor M, Keogh JB. Hand grip dynamometry as a predictor of postoperative complications reappraisal using age standardized grip strengths. J Parenter Enter Nutr. 1989;13:30-3.

24. Younossi ZM, Stepanova M, Zeuzem S, Dusheiko G, Esteban R, Hezode C, Reesink HW, et al. Patientreported outcomes assessment in chronic hepatitis $\mathrm{C}$ treated with sofosbuvir and ribavirin: the VALENCE study. J Hepatol. 2014;61:228-34.

25. Younossi ZM, Stepanova M, Nader F, Lam B, Hunt $\mathrm{S}$. The patient's journey with chronic hepatitis $\mathrm{C}$ from interferon plus ribavirin to interferon- and ribavirin-free regimens: a study of health-related quality of life. Aliment Pharmacol Ther. 2015;42:286-95.

26. Younossi ZM, Stepanova M, Sulkowski M, Foster GR, Reau N, Mangia A, Patel K, et al. Ribavirin-free regimen with sofosbuvir and velpatasvir is associated with high efficacy and improvement of patient-reported outcomes in patients with genotypes 2 and 3 chronic hepatitis c: results from Astral-2 and -3 clinical trials. Clin Infect Dis. 2016;63:1042-8.

27. Strazzabosco M, Allen JI, Teisberg EO. Value-based care in hepatology. Hepatology. 2017;65:1749-55. 
28. Younossi ZM, Stepanova M, Afdhal N, Kowdley KV, Zeuzem S, Henry L, Hunt SL, et al. Improvement of health-related quality of life and work productivity in chronic hepatitis C patients with early and advanced fibrosis treated with ledipasvir and sofosbuvir. J Hepatol. 2015;63:337-45.

29. Bruchfeld A, Roth D, Martin P, Nelson DR, Pol S, Londoño M-C, Monsour H, et al. Elbasvir plus grazoprevir in patients with hepatitis $\mathrm{C}$ virus infection and stage $4 ? 5$ chronic kidney disease: clinical, virological, and health-related quality-of-life outcomes from a phase 3, multicentre, randomised, double-blind, placebo-controlled trial. Lancet Gastroenterol Hepatol. 2017. https://doi.org/10.1016/ S2468-1253(17)30116-4.

30. Younossi ZM, Stepanova M, Feld J, Zeuzem S, Sulkowski M, Foster GR, Mangia A, et al. Sofosbuvir and velpatasvir combination improves outcomes reported by patients with HCV infection, without or with compensated or decompensated cirrhosis. Clin Gastroenterol Hepatol. 2016. https://doi.org/ 10.1016/j.cgh.2016.10.037.

31. Younossi ZM, Stepanova M, Feld J, Zeuzem S, Sulkowski M, Foster GR, Mangia A, et al. Sofosbuvir and velpatasvir combination improves patient-reported outcomes for patients with HCV infection, without or with compensated or decompensated cirrhosis. Clin Gastroenterol Hepatol. 2017;15(421-430):e6.

32. Walsh CE, Workowski K, Terrault NA, Sax PE, Cohen A, Bowlus CL, Kim AY, et al. Ledipasvir-sofosbuvir and sofosbuvir plus ribavirin in patients with chronic hepatitis $\mathrm{C}$ and bleeding disorders. Haemophilia. 2017;23:198-206.

33. Stedman CAM, Hyland RH, Ding $\mathrm{X}$, Pang PS, McHutchison JG, Gane EJ. Once daily ledipasvir/sofosbuvir fixed-dose combination with ribavirin in patients with inherited bleeding disorders and hepatitis $\mathrm{C}$ genotype 1 infection. Haemophilia. 2016;22:214-7.

34. Walsh M, Macgregor D, Stuckless S, Barrett B, Kawaja M, Scully M-F. Health-related quality of life in a cohort of adult patients with mild hemophilia A. J Thromb Haemost. 2008;6:755-61.

35. St-Louis J, Urajnik DJ, Ménard F, Cloutier S, Klaassen RJ, Ritchie B, Rivard GE, et al. Generic and disease-specific quality of life among youth and young men with Hemophilia in Canada. BMC Hematol. 2016;16:13.

36. Horne R, Parham R, Driscoll R, Robinson A. Patients' attitudes to medicines and adherence to maintenance treatment in inflammatory bowel disease. Inflamm Bowel Dis. 2009;15:837-44.

37. Aikens JE, Nease DE, Nau DP, Klinkman MS, Schwenk TL. Adherence to maintenance-phase antidepressant medication as a function of patient beliefs about medication. Ann Fam Med. 2005;3:23-30.

38. Petersen T, Townsend K, Gordon LA, Sidharthan S, Silk R, Nelson A, Gross C, et al. High adherence to all-oral directly acting antiviral HCV therapy among an inner-city patient population in a phase 2a study. Hepatol Int. 2016;10:310-9.

39. Younossi ZM, Stepanova M, Henry L, Nader F, Younossi Y, Hunt S. Adherence to treatment of chronic hepatitis C: from interferon containing regimens to interferon and ribavirin free regimens. Medicine (Baltimore). 2016;95:e4151.

40. Davis KL, Mitra D, Medjedovic J, Beam C, Rustgi V. Direct economic burden of chronic hepatitis $C$ virus in a United States managed care population. J Clin Gastroenterol. 2011;45:e17-24.

41. McCombs JS, Yuan Y, Shin J, Saab S. Economic burden associated with patients diagnosed with hepatitis C. Clin Ther. 2011;33:1268-80.

42. El Khoury AC, Vietri J, Prajapati G. The burden of untreated hepatitis C virus infection: a US patients' perspective. Dig Dis Sci. 2012;57:2995-3003.

43. daCosta DiBonaventura M, Yuan Y, Lescrauwaet B, L'Italien G, Liu GG, Kamae I, Mauskopf JA. Multicountry burden of chronic hepatitis $C$ viral infection among those aware of their diagnosis: a patient survey. PLoS ONE 2014;9:e86070.

44. Huisman EJ, van Meer S, van Hoek B, van Soest H, van Nieuwkerk KMJ, Arends JE, Siersema PD, et al. Effects of preventive versus 'on-demand' nutritional support on paid labour productivity, physical exercise and performance status during PEG-interferon-containing treatment for hepatitis C. Clin Res Hepatol Gastroenterol. 2016;40:221-9. 